\title{
Evaluating on flooding area and tidal beach change in Quang Ninh coastal zone due to sea level rise
}

\author{
Tran Thu Ha ${ }^{1,2}$, Dinh Van Manh ${ }^{2,3, *}$, Truong Manh Chien ${ }^{3}$
}

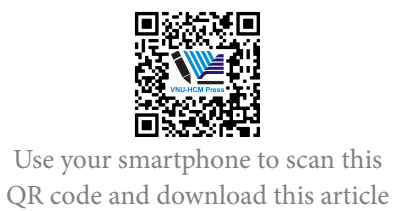

${ }^{1}$ Quang Ninh Environment and Natural Resource Department, Vietnam

${ }^{2}$ Graduate University of Science and Technology, VAST, Vietnam

${ }^{3}$ Institute of Mechanics, VAST, Vietnam

Correspondence

Dinh Van Manh, Graduate University of Science and Technology, VAST, Vietnam Institute of Mechanics, VAST, Vietnam

Email: dvmanh@imech.vast.vn

History

- Received: 25-12-2019

- Accepted: 01-12-2020

- Published: 31-12-2020

DOI : 10.32508/stdjet.v3iSI3.650

\section{Check for updates}

Copyright

(c) VNU-HCM Press. This is an openaccess article distributed under the terms of the Creative Commons Attribution 4.0 International license.

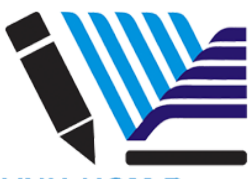

VNU-HCM Press

\begin{abstract}
Viet Nam is considered one of countries most affected by climate change and sea-level rise. It results in many negative effects, such as flooding, saline intrusion and beach erosion occurred in the coastal zones. Quang Ninh with more than $250 \mathrm{~km}$ coastline, located in the northeastern part of Vietnam, is one of the vulnerable coastal provinces under the heavily affected due to the sea level rise. In order to evaluate the changes of flooded areas and tidal beaches due to the sea level rise in Quang Ninh coastal zone a 2D numerical model is set up, using the 3-grids nesting technique. The numerical model is calibrated by using the harmonic constants of 8 tidal constituents at Hon Dau tide station and validated with the observed data. On the basis of the climate change scenarios (RCP4.5, RCP8.5) in the period from 2020 to 2100, the corresponding sea level values are used in the numerical modeling to calculate the changes of flooded areas and tidal beaches due to the sea level rise. The obtained results on changing of the flooded area and tidal beach in Quang Ninh coastal zone are not only statically by changing water sea levels but also due to changing of the tidal range in this area. The calculated results point out that districts under the most affected of the sea level rise are Quang Yen, Tien Yen, Hai Ha, Mong Cai.
\end{abstract}

Key words: Sea level rise, tidal beach, numerical model, Quang Ninh coastal zone

\section{INTRODUCTION}

Viet Nam is considered as one of countries most affected by climate change. Over the past years, under the impact of climate change, the frequency and intensity of natural disasters are increasing, caused huge loss of human life, property, infrastructure, economy, society and lead to the bad influence on environment. The sea level rise (one of main consequences of the Climate change) can cause many negative effects on coastal zones, such as flooding, saline intrusion, beach erosion etc. Since 2009, The Ministry of Natural Resources and Environment developed and published the climate change and sea level rise scenarios to promptly serve ministries, sectors and localities to implement the National Target Program to Respond to Climate Change. These scenarios then were updated in 2011, 2016 based on data sources, specific climatic conditions of Viet Nam and the results from climate models at the time and could be used as the basis orientation for ministries, provinces and localities to assess the potential impacts of climate change, develop and implement effective plans to respond to climate change and sea level rise ${ }^{1}$.

Quang Ninh is a province along the northeastern coast of Vietnam. There are more than 2,000 islands, extending along the coast for more than $250 \mathrm{~km}$. The sea bottom topography of Quang Ninh isn't smooth, and has an average depth of $20 \mathrm{~m}$. The tide in Quang Ninh sea area is diurnal with the maximum range above $4 \mathrm{~m}$, the largest in the North of Vietnam. Therefore, Quang Ninh is one of the vulnerable coastal provinces under the affects of inundation, saline intrusion and beach erosion due to the climate change and the sea level rise.

In this study, on the basis of the climate change scenarios issued by The Ministry of Natural Resources and Environment in 2016, the changes of flooded areas and tidal beaches due to the sea level rise after the scenarios (averaged) RCP4.5 and (highest) RCP8.5 for the period from 2020 to 2100 are calculated and evaluated. The changes of flooded area and tidal beach in Quang Ninh coastal zone are considered not only statically by changing of water sea levels but also due to changing of the tidal range in this area by using a numerical hydrodynamic model for the East Vietnam Sea and Quang Ninh coastal zone.

\section{DATA AND METHODS}

In order to setup and to verify the numerical model to evaluate changes of flooded area, tidal beach due to the sea level rise in Quang Ninh coastal zone, the following data were collected and analyzed:

- Bathymetry data: The depth map scaled 1/1,000,000 by Vietnamese Navy, 1991; Topography map scaled 
$1 / 100,000$ in the coastal and sea of Quang Ninh, supported by Quang Ninh Environment and Natural Resource Department.

The sea bed data from different sources are assimilated and presented in Figure 1.

- Seawater level and tide harmonic constant data:

+ Hourly seawater levels for one year (2017) and in the time period from $01 / 9 / 2018$ to $01 / 10 / 2018$ at the tide station Hon Dau, Hai Phong province.

However, on the basis of the tidal regime in the study are, only 8 tidal constituents are taken into account. They consist of 4 diurnal tides $\left(\mathrm{K}_{1}, \mathrm{O}_{1}, \mathrm{P}_{1}, \mathrm{Q}_{1}\right)$, and 4 semi-diurnal $\left(\mathrm{M}_{2}, \mathrm{~S}_{2}, \mathrm{~N}_{2}, \mathrm{~K}_{2}\right)$.

+ Hourly sea levels along the open boundary of the numerical model are received from another numerical model covered the whole East Sea.

\section{NUMERICAL MODEL SETUP}

The $2 \mathrm{D}$ shallow water equations is quite suitable to simulate seawater level variation due to tide and sea level rise. Under the shallow water assumption, which say the vertical length scale is much smaller than the horizontal one, the momentum and continuity equations are expressed in the spherical coordinate as follows $^{2}$ :

$$
\begin{gathered}
\frac{\partial U}{\partial t}+\frac{U}{R \cos \varphi} \frac{\partial U}{\partial \lambda}+\frac{V}{R \cos \varphi} \frac{\partial(U \cos \varphi)}{\partial \varphi} \\
-\frac{U V \tan \varphi}{R}=2 \omega \sin \varphi V-\frac{g}{R \cos \varphi} \frac{\partial \xi}{\partial \lambda} \\
-k_{b} \frac{U \sqrt{U^{2}+V^{2}}}{H}+\frac{1}{R \cos \varphi} \frac{\partial P_{a}}{\partial \lambda}+\frac{\tau_{\lambda}^{s}}{H} . \\
\frac{\partial V}{\partial t}+\frac{U}{R \cos \varphi} \frac{\partial V}{\partial \lambda}+\frac{\partial V}{\partial \varphi}+\frac{U^{2} \tan \varphi}{R} \\
=2 \omega \sin \varphi U-\frac{g}{R} \frac{\partial \xi}{\partial \varphi} \\
-k_{b} \frac{V \sqrt{U^{2}+V^{2}}}{H}+\frac{1}{R} \frac{\partial P_{a}}{\partial \varphi}+\frac{\tau_{\varphi}^{s}}{H} \\
\frac{\partial \xi}{\partial t}+\frac{1}{R \cos \varphi}\left\{\frac{\partial}{\partial \lambda}(H U)+\frac{\partial}{\partial \varphi}(H V \cos \varphi)\right\}=0 .
\end{gathered}
$$

where, $\lambda$ and $\varphi$ are coordinates in the eastward and northward directions respectively; $t$ - time; $\xi$ - sea level height above the mean sea surface; $h$ - water depth below the mean sea surface; $H=h+\xi$ - total water column; $R$ - earth radius; $\omega$ - earth's rotation velocity; $g$ - acceleration of gravity; $P_{a}$ - air pressure at sea surface; and - wind stresses in $\lambda$ and $\varphi$ direction respectively; $k_{b}$ - bottom friction coefficient; $U$, $V$ - depth-averaged velocity component, and specified by ${ }^{3}$ :

$$
\begin{aligned}
& U=\frac{1}{h+} \int_{-h}^{\xi} \square u(z) d z, \\
& V=\frac{1}{h+} \int_{-h}^{\xi} \square v(z) d z
\end{aligned}
$$

where $u(z)$ and $v(z)$ are velocity components in $\lambda$ and $\varphi$ directions respectively at $\mathrm{z}$ level.

The equations (3.1) - (3.3) are closed by the below initial and boundary conditions.

Initial conditions: at the initial time $t=0, U=V=\xi$ $=0$.

Boundary conditions: at the solid boundaries, the impermeable condition is accepted. At the open boundaries, the sea water levels are predefined ${ }^{4}$.

The finite difference method is applied to solve the above mentioned equations by using the noncollocated grid, the leap-frog difference scheme, nesting technique and wet-dry treatment ${ }^{5}$.

In order to simulate the tide oscillation in the Quang Ninh coastal area, a numerical model with two nesting grids, as shown in Figure 2, is setup. The coarse grid covers the whole of The Gulf of Tonkin, using the grid step of 1/20 degrees (about $500 \mathrm{~m}$ ) in longitude and latitude respectively. The fine grid with the grid step of $1 / 200$ degrees concentrated on the nearby shoreline of Quang Ninh Province.

The numerical model has calibrated by comparisons between the calculated water levels and the observed data in the some specified time periods depending on the data available. The calibration process is to modify the value of the bottom friction coefficient and tidal harmonic constants at open boundary reasonably in order to obtain the calculated results in a good agree with the observed ones. Because in the numerical model, the water levels are contributed by 8 tidal constituents, therefore the calibration process is spitted into each individual constituent and its amplitude and phase will be taken into the comparison Table 1. presents the comparison between the calculated and analyzed harmonics constants (amplitude and phase) of 8 tidal constituents in the Hondau tide gauge station.

Next, the numerical model has validated by calculating the tide by using the chosen parameters and comparing with the observed water levels at Hon Dau from $01 / 9 / 2019$ to $30 / 9 / 2019$ as shown in Figure 3. The compared results show that the numerical model has been verified well enough in order to simulate the tide oscillation in the Quang Ninh near coast area.

\section{CALCULATING SCENARIOS}

The calculating scenarios in this study are established on the basis of the Climate Change and Sea Level Rise Scenarios for Viet Nam, was published by the Ministry of Natural Resources and Environment in 2016. Under the average Representative Concentration Pathways, RCP4.5, scenario, the sea water level will rise of $55 \mathrm{~cm}$ by the end of 21st Century (called 


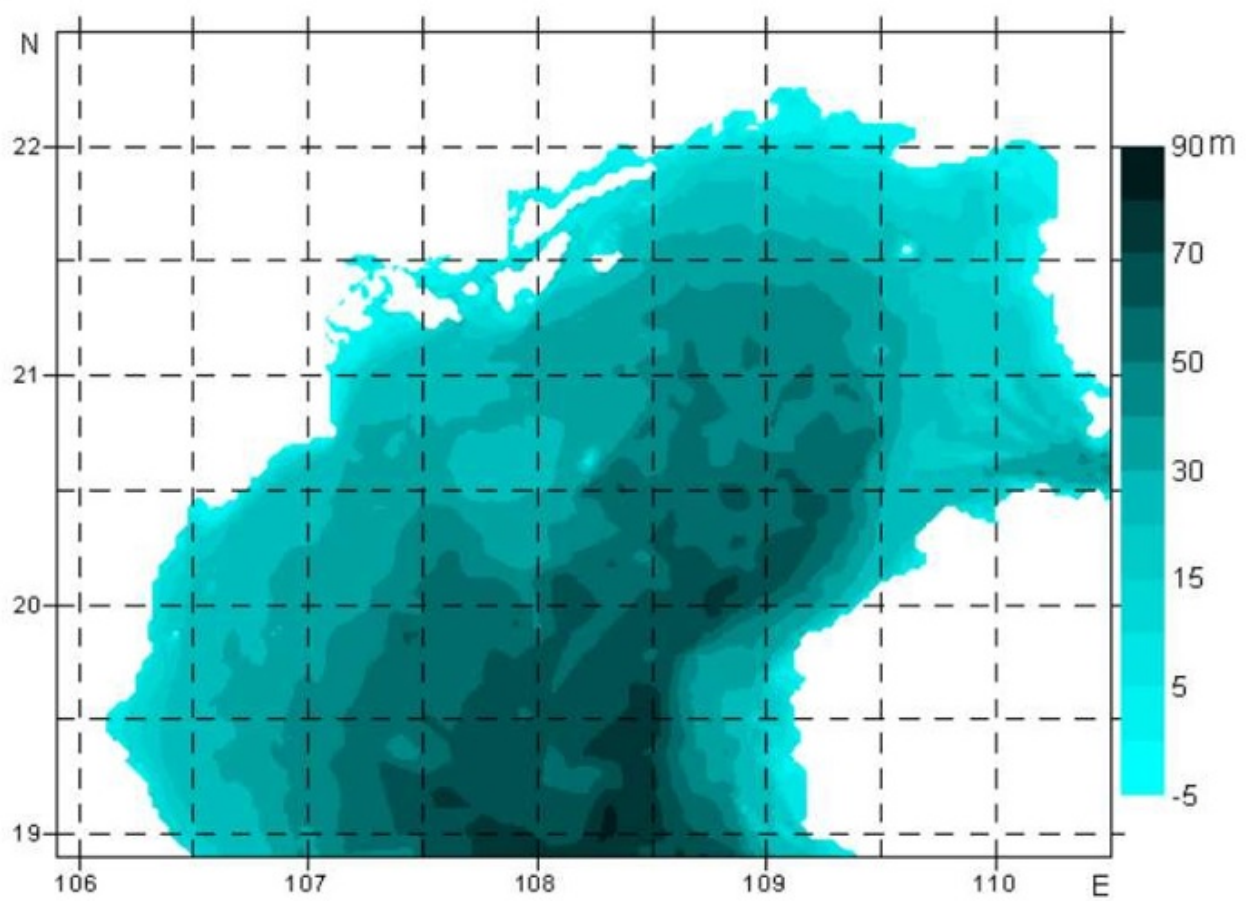

Figure 1: Depth map in the Quang Ninh sea area and vicinity.

Table 1: Calculated and analyzed tidal harmonic constants at Hon Dau tidal gauge station.

\begin{tabular}{|c|c|c|c|c|c|c|c|}
\hline \multirow[t]{2}{*}{ Tidal constituent } & \multicolumn{2}{|l|}{ Analyzed } & \multicolumn{2}{|l|}{ Calculated } & \multicolumn{3}{|c|}{ errors } \\
\hline & Amplitude & Phase & Amplitude & Phase & Ampl & le cm (\%) & Phase \\
\hline K1 & 68.2 & 106 & 67.5 & 107 & -0.71 & 1.0 & 0.1 \\
\hline $\mathrm{O} 1$ & 75.7 & 33 & 74.9 & 35 & -0.78 & 1.0 & 0.2 \\
\hline M2 & 5.6 & 67 & 6.4 & 43 & 0.83 & 15.0 & -0.8 \\
\hline S2 & 4.4 & 131 & 4.7 & 103 & 0.34 & 9.0 & -0.9 \\
\hline $\mathrm{N} 2$ & 0.7 & 79 & 0.8 & 36 & 0.07 & 17.0 & -1.5 \\
\hline K2 & 2.3 & 110 & 2.6 & 80 & 0.34 & 17.0 & -1 \\
\hline P1 & 21.4 & 98 & 20.7 & 107 & -0.65 & 3.0 & 0.6 \\
\hline Q1 & 14.8 & 355 & 14.2 & 7 & -0.61 & 4.0 & 0.9 \\
\hline
\end{tabular}

calculating scenario CS01), and the sea water level will rise of $75 \mathrm{~cm}$ (CS02) are considered. Similarly, under the highest RCP8.5 scenario, the CS03 with sea level rise of $80 \mathrm{~cm}$ and CS04 with sea level rise of $106 \mathrm{~cm}$ by the end of 21 st Century are calculated.

The calculated results of tidal oscillation under the above scenarios (CS01 - CS04) will be compared with the calculated results at the present state (CSO0). It is noted that the calculating scenarios from CSO1 to
CS04 are carried out by using the same model parameters, forcing and boundary conditions except the water depth $h$ added by the value of sea level rises respectively.

In Figure 4 the difference of calculated sea levels in the case CSO1 in comparison with the case CSO0 at Hon Gai station for a month is presented. Similarly, Figures 5, 6 and 7 are for the cases of CS02, CS03 and CS04, respectively. It is shown that differences are 


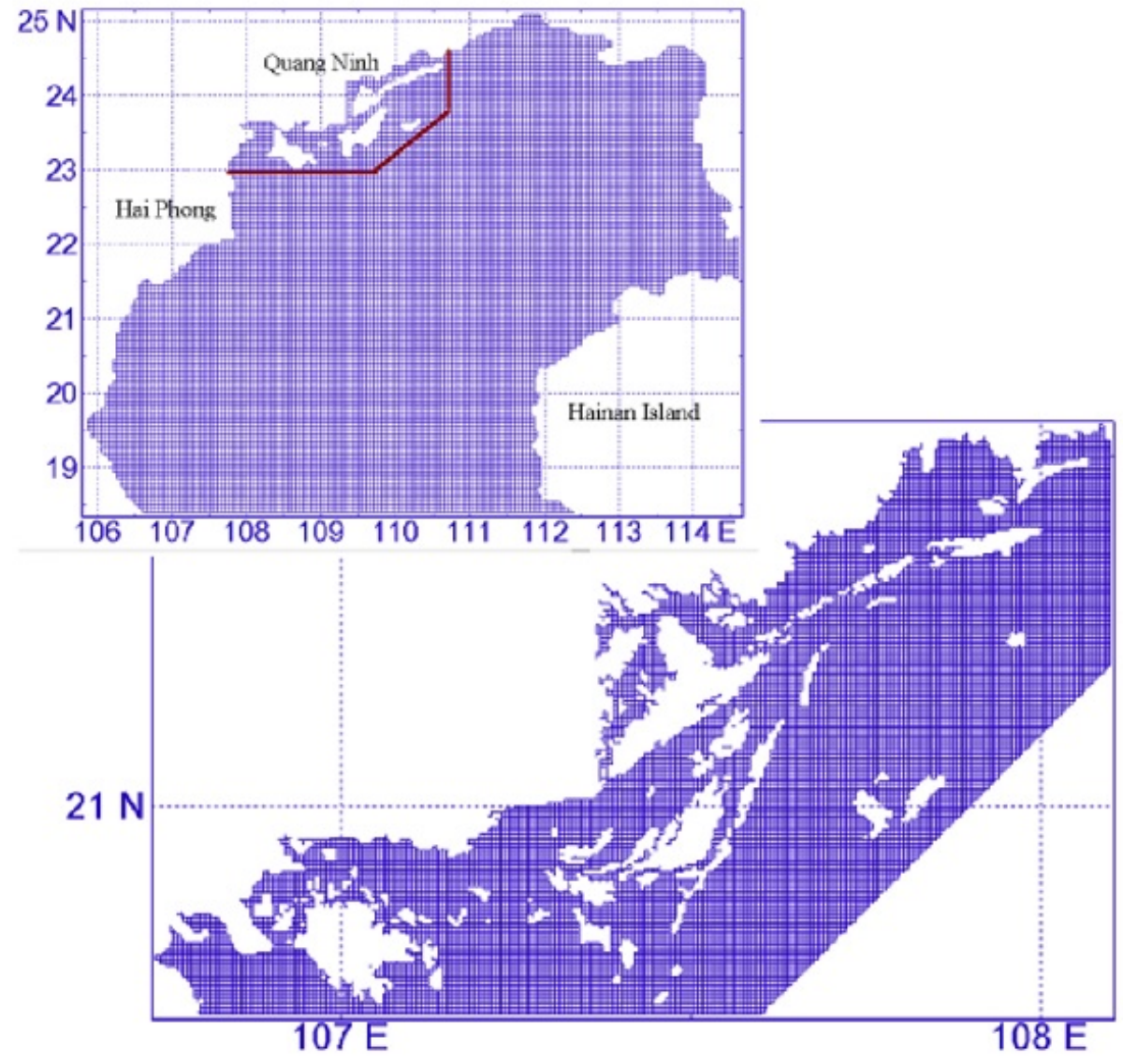

Figure 2: Grid layout of the numerical model: coarse grid (upper) and fine grid (lower).

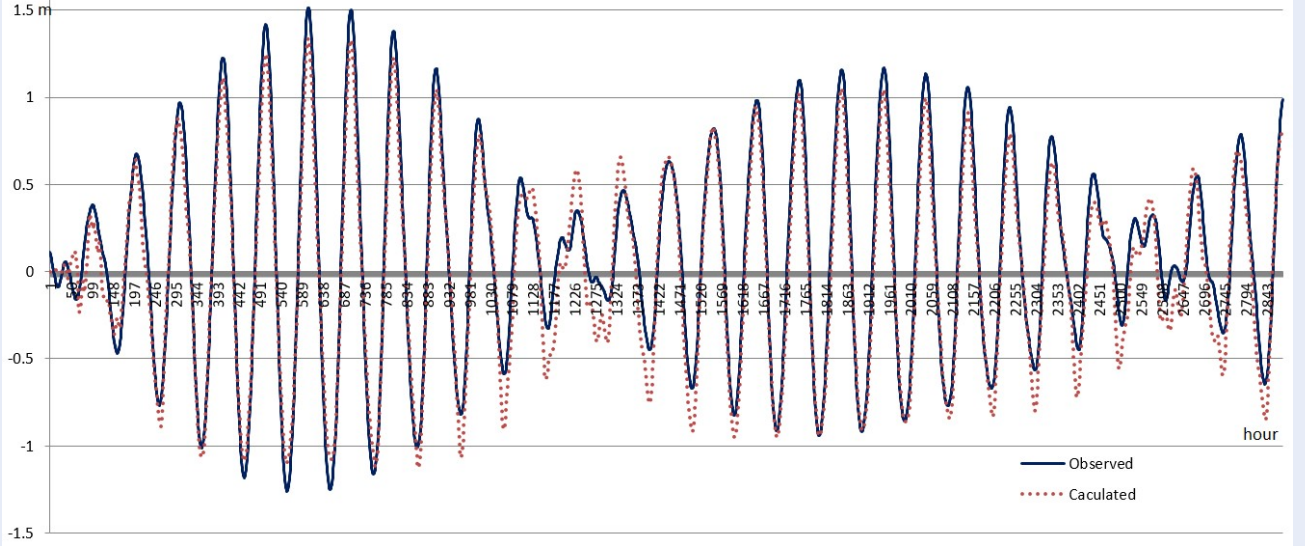

Figure 3: Calculated and observed water levels during the September 2019 at Hon Dau station. 


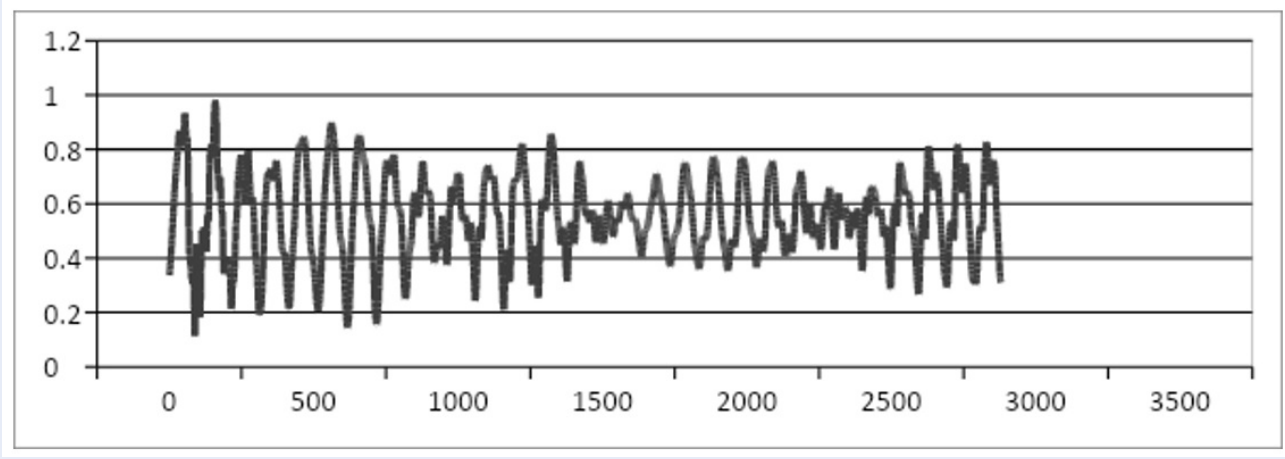

Figure 4: Difference of the calculated sea levels (CS01 - CS00) at Hon Gai station for a month.

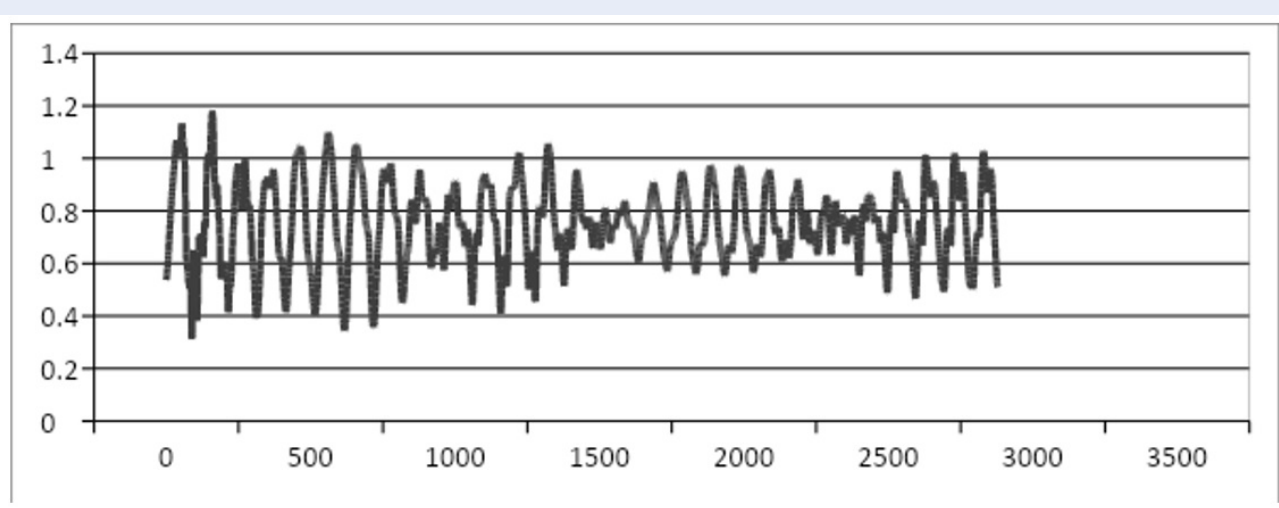

Figure 5: Difference of the calculated sea levels ( $\mathrm{CSO} 2$ - $\mathrm{CSO0})$ at Hon Gai station for a month.

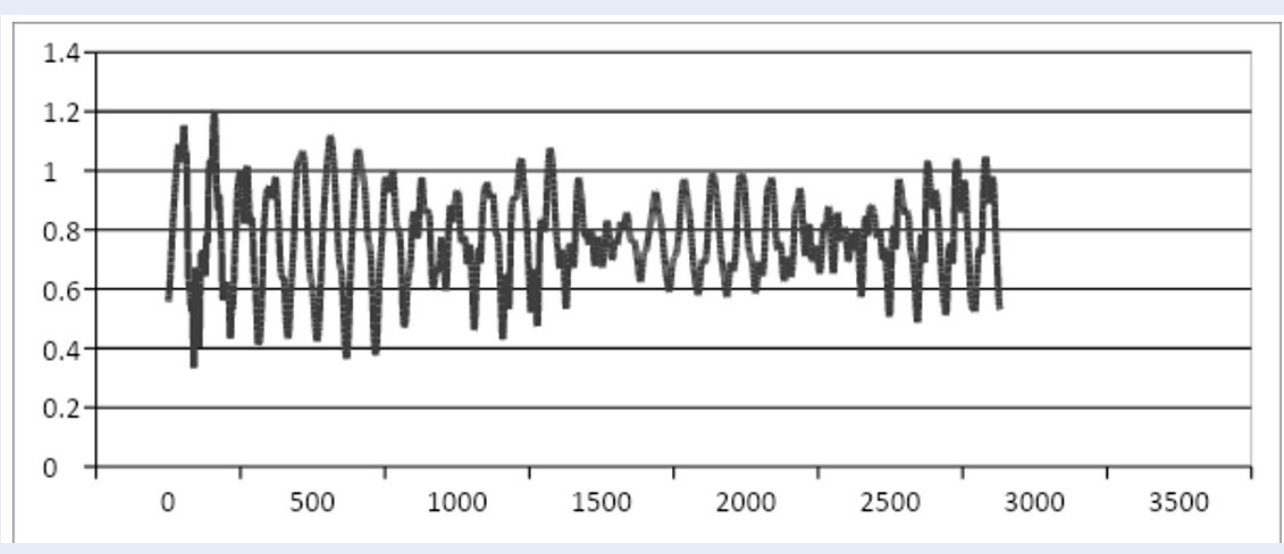

Figure 6: Difference ofthe calculated sea levels (CS03 - CSO0) at Hon Gai station for a month. 


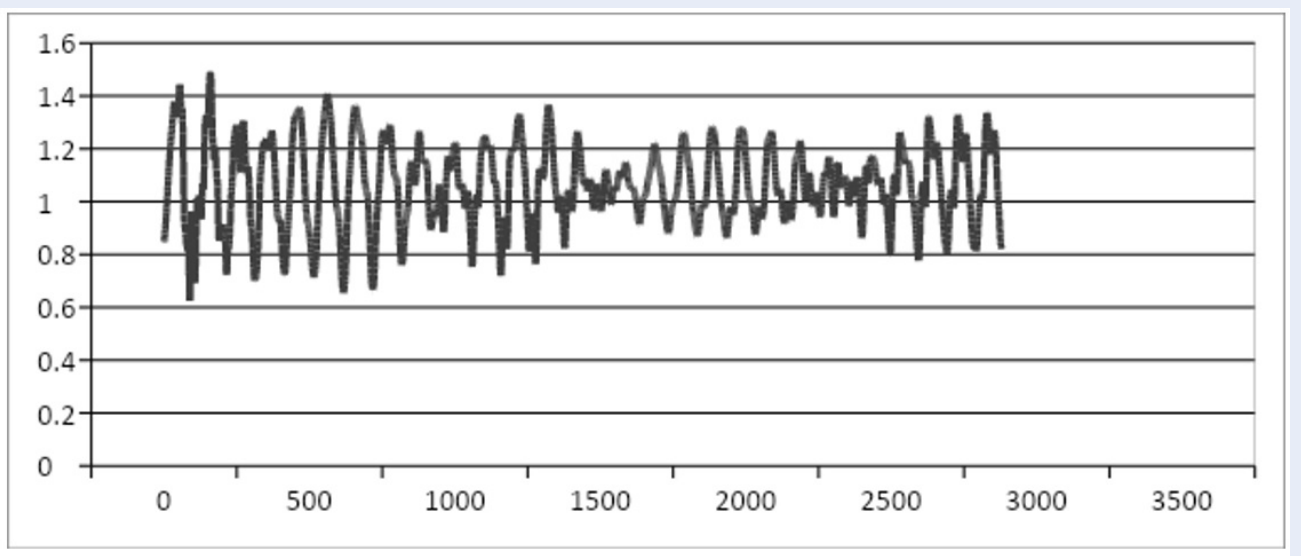

Figure 7: Difference of the calculated sea levels (CSO4 - CS00) at Hon Gai station for a month.

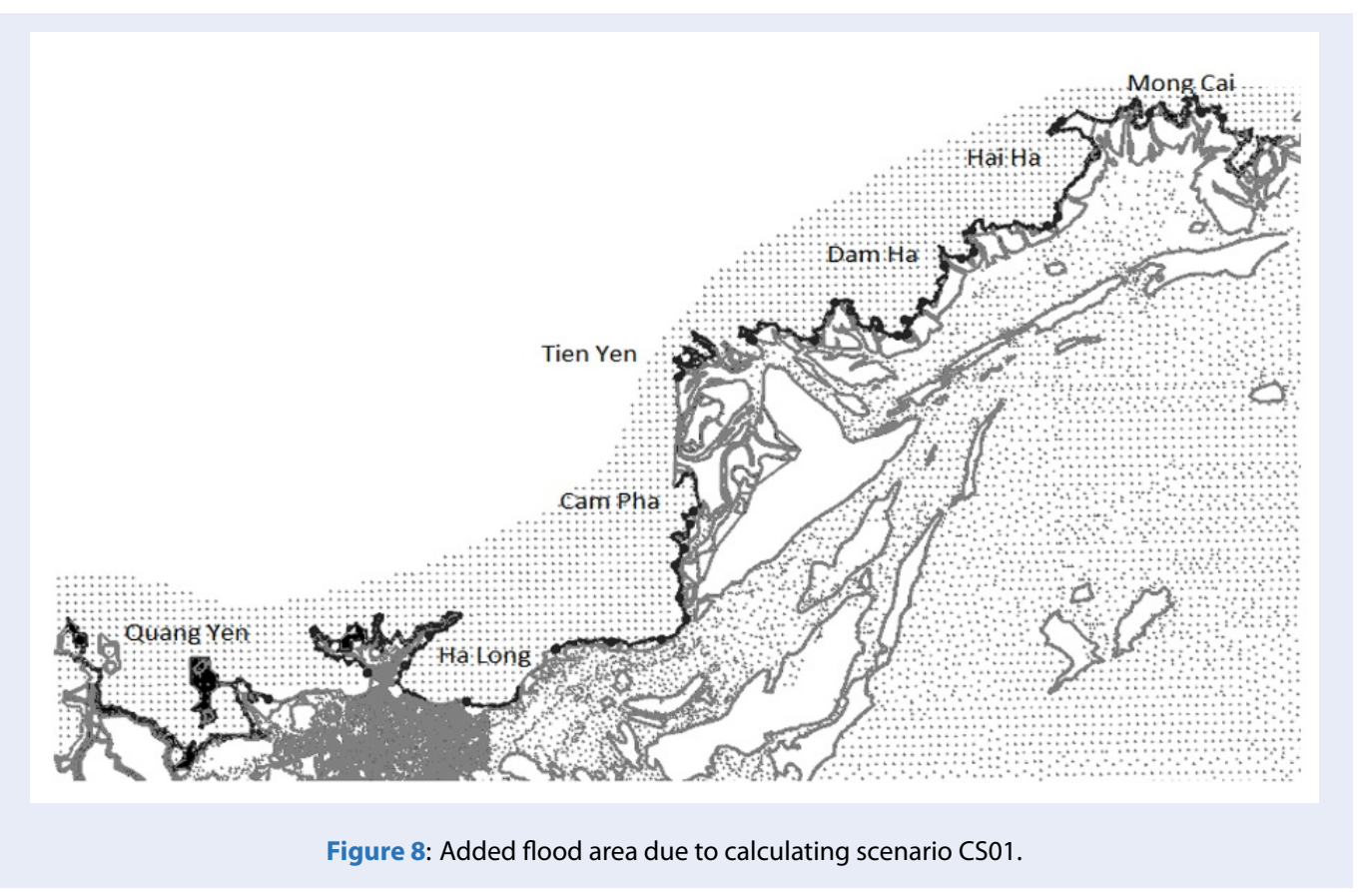

significant, greater than $0.5 \mathrm{~m}$ in some time moments, and changed depending the tide time periods. During spring tide the difference is much larger than during neap tide. Furthermore, the mean sea level is higher the difference is larger. The maximum difference for cases CS01, CS02, CS03 and CS04 are 0.42, 0.58, 0.60 and $0.65 \mathrm{~m}$, respectively.

On the basis of the calculated tide oscillations of calculating scenarios in a long time period, the added flood land for each case has been evaluated. The added flood area means the area of land zones to be flood due to the sea level rise. Figure 8 to Figure 11 illustrate the added flood land (dark zone) under con- ditions of the cases CS01, CS02, CS03 and CS04. The total flood area of 4 cases are approximately 80, 111, 132 and $199 \mathrm{~km}^{2}$, respectively.

In general, in districts Quang Yen, Tien Yen, Dam Ha, Hai Ha and Mong Cai, there are the added flood areas larger than the remain districts of Quang Ninh. These are the districts occupied low land zones and estuaries.

However, changing of tide range in the study area is not significant, only several centimeters. That means the difference is controlled mainly by changing of tide phase at the considered point (Hon Gai station location). The station is fixed in space but changed rel- 


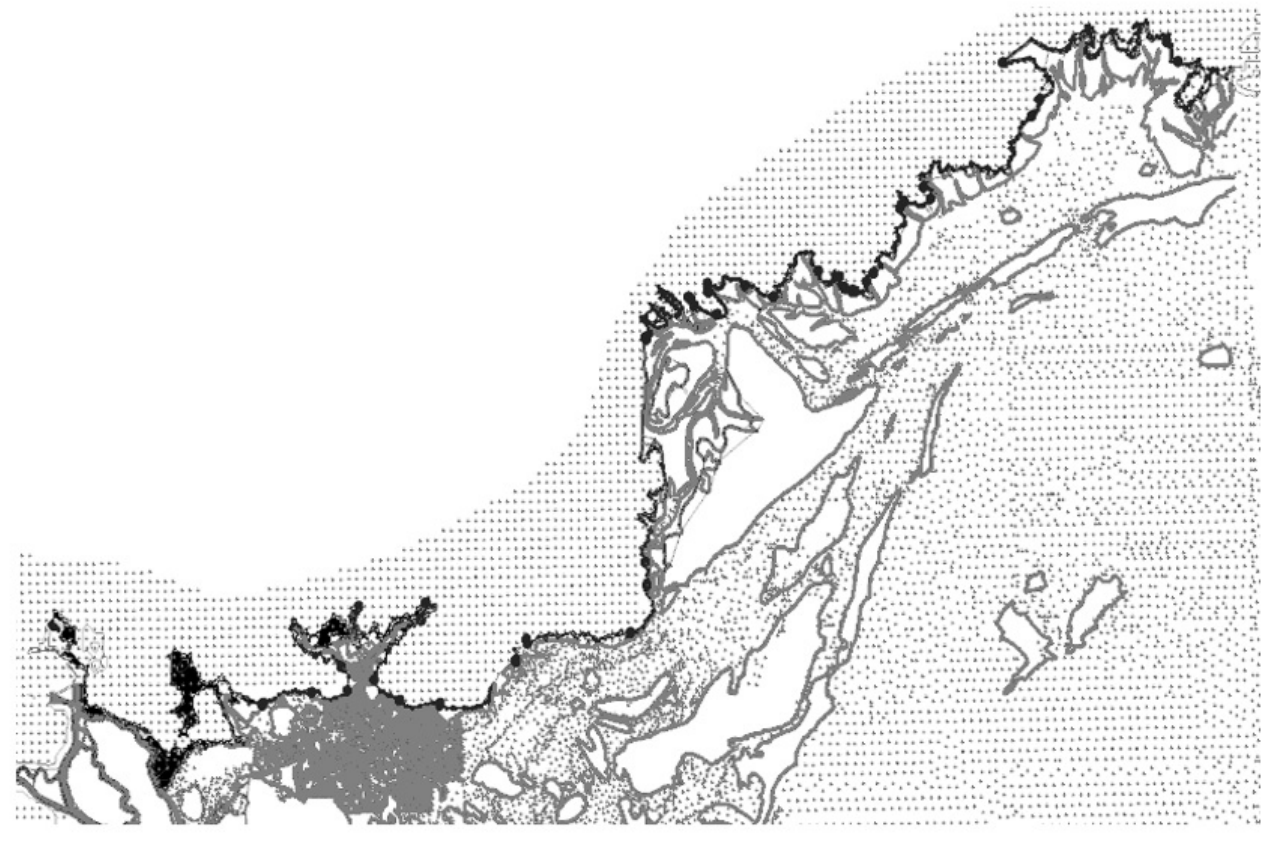

Figure 9: Added flood area due to calculating scenario CSO2.

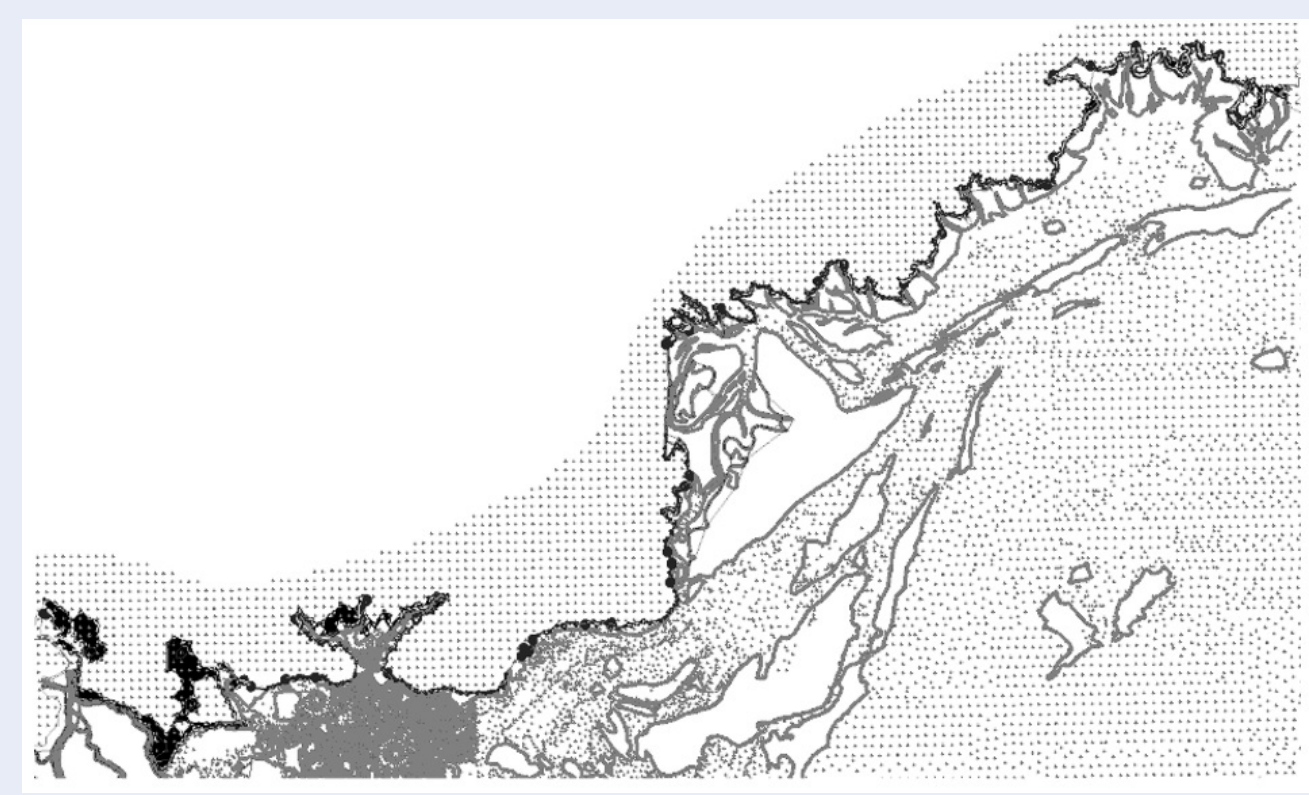

Figure 10: Added flood area due to calculating scenario CSO3. 


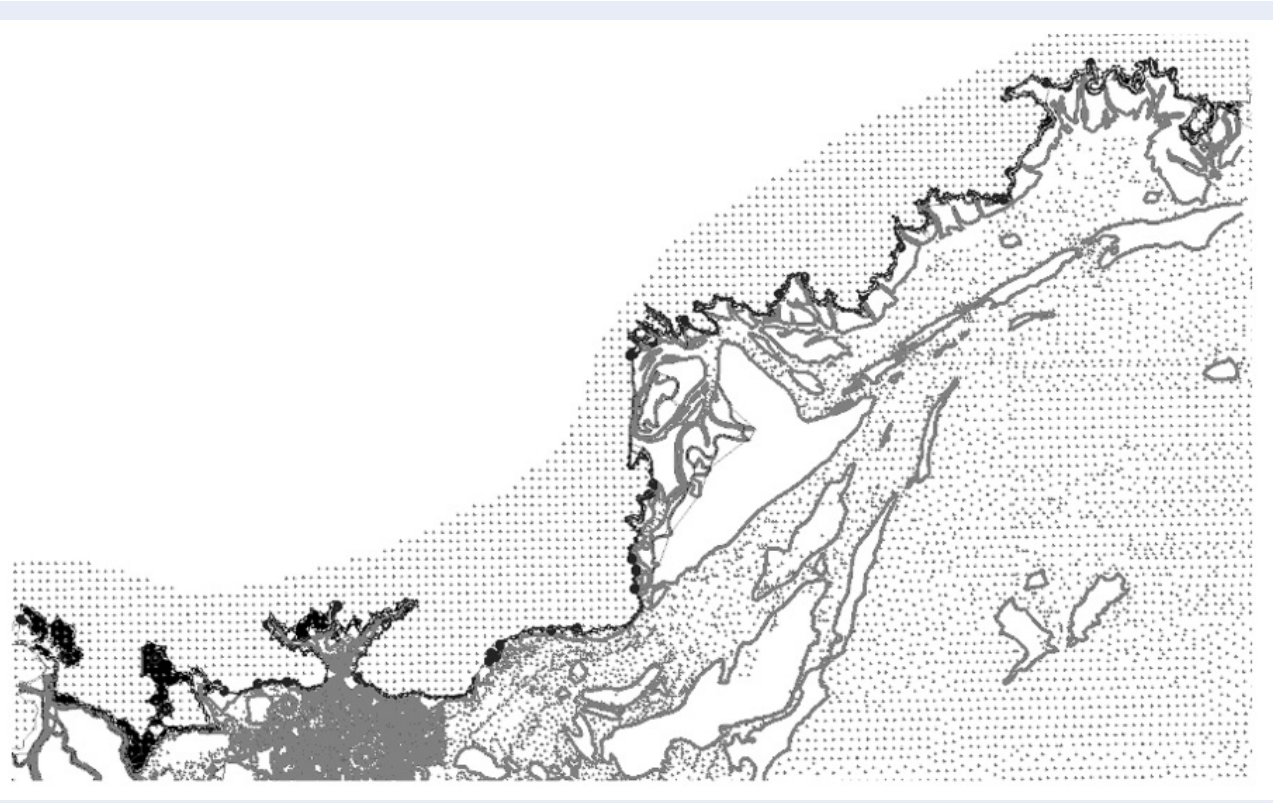

Figure 11: Added flood area due to calculating scenario CS04.

atively to the shoreline (the edge of sea and land) because when the sea level rise the shoreline will be landwards.

\section{CONCLUSIONS AND DISCUSSION}

In this study, the numerical model using grid nesting techneque is setup and validated with the measured sea level data at Hon Dau station. This numerical model then is applied to simulate the tide oscillation in the Quang Ninh sea area under the various climate change, namedly two scenarios RCP4.5 and RCP8.5 with the average and maximun sea level rise values chosen.

The obtained calculated results indicate that in Quang Ninh province, the districts such as Quang Yen, Tien Yen, Dam Ha, Hai Ha and Mong Cai have more vulnerable coastal zone than other districts. Ha long, the most important region for tourism development of Quang Ninh, only in average is vulnerable. Due to sea level rise, under the maximum scenario, Quang Ninh will be lost up to about $200 \mathrm{~km}^{2}$ land area.

\section{ACKNOWLEDGMENT}

The research funding from projects "Nghiên cứu đánh giá và đề xuất giải pháp phòng tránh dòng RIP tại các bãi tắm du lịch tỉnh Hà Tĩnh”, code VAST.NĐP.01/1617, and "Hỗ trợ hoạt động nghiên cứu khoa học cho nghiên cứu viên cao cấp", code NCVCC03.03/19-19 were acknowledged.

\section{CONFLICT OF INTEREST}

We declare that there is no conflict of whatsoever involved in publishing this research.

\section{AUTHOR CONTRIBUTIONS}

All authors contributed equally to this work. All authors have read and agreed to the published version of the manuscript.

\section{REFERENCES}

1. Thuc $T$, et al. The climate change and sea level rise scenarios for Vietnam. Ministry of Natural Resources and Environment. 2016;p. 1-170.

2. Choi BH, Kim DG, Kim DH. A numerical Tidal model for the Southeast Asian Seas. J Korean Soc of Coast and Oc Engrs. 1994;6(2):115-139.

3. Mazzega $P$, Berge $M$. Ocean tides in the Asian semi enclosed seas from TOPEX/POSEIDON. J Geophys Res. 1994;99(C12):24867-24881. Available from: https://doi.org/10. 1029/94JC01756.

4. Kien NC, Manh DV, Co NT. An evaluation of typhoon surge propagation into river system by using the coupling model 1 2D. J of Marine Science and Technology. 2013;1(T13):95-104.

5. C N, V D, Lai HV. Salinity intrusion in the south-west coastal zone of Vietnam. J of Marine Science and Technology. 2014;4(T14):299-309. Available from: https://doi.org/10.15625/ 1859-3097/14/4/5462. 